\title{
Küresel Ekonomik Sistemde Türk Tekstil Sektörünün Ürün Haritalaması Modeliyle Analizi
}

\author{
Ahmet Can BAKKALCI*
}

$\ddot{O} Z$

Bu çalışma Türk tekstil sektörünün dünya ile yaptı̆̆ dış ticareti incelemektedir. Küresel ekonomik sistemde yer alan tekstil endüstrisi Çin'in Dünya Ticaret Örgütü üyeliğinden sonra değişmeye devam etmektedir. Dünya tekstil endüstrisi Çin ve Avrupa Birliği üyesi ülkeler tarafindan yönlendirilmektedir.

Çalışmada tekstil sektörünün rekabet yapısını açıklayabilmek için "Revealed Comperative Advantage" Açıklanmış Karşılaştırmalı Üstünlükler Endeksi (RCA), "Revealed Symmetric Conperative Advantage”, Açıklanmış Simetrik Karşılaş̧ırmalı Üstünlükler Endeksi (RSCA), ve "Trade Balance Index" Ticaret Dengesi Endeksi (TBI) yöntemleri kullanılmıştır. Ayrıca Türk tekstil sektörünün rekabet yapısını belirleyebilmek için Ürün Haritalaması Yöntemi'ne başvurulmuştur. Bu analizle tekstil sektörü içindeki belirleyici alt sektör saptanmıştır.

Rekabet gücü Türk tekstil sektöründe yer alan 15 madde grubu için 2001-2016 dönemi açısından ABD Doları cinsinden incelenmiştir. Dış ticaret verileri ITC istatistiklerinden derlenmiştir.

Anahtar Kelimeler: Ürün Haritalamasl, Tekstil Endüstrisi, Rekabet

JEL Kodlart: F12, F14.

\section{Analysis of Turkish Textile Sector in The Global Economic System with Product Mapping Model}

\begin{abstract}
This study examines the foreign trade of the Turkish textile industry with the world. The textile industry in the global economic system continues to change after China's membership in the World Trade Organization. World textile industry dominated by China and EU's members.

Revealed Comperative Advantage" (RCA), "Revealed Symmetric Conperative Advantage" (RSCA), and "Trade Balance Index" (TBI) methods have been used in the study to explain textile sector's competition structure. We also use The Product Mapping Analyse to determine the competitiveness of the Turkish textile sector. This analyse determined leading sub textile sector. The product mapping uses two analysis tools. First tool is comparative advantage and the second one is TBI.

Competitiveness has been examined in terms of US Dollar for the period of 2001-2016. 15 subgroups of items in the Turkish textile sector analysed. Foreign trade data are compiled from ITC statistics.
\end{abstract}

Key Words: Product Mapping, Textile Industries, Competition.

JEL Codes: F12, F14

\section{GíRiş}

Küresel sistemde ticaret yapısı hızla değişmekte ve sermaye yoğun üretime doğru evrilmektedir. Küresel dış ticarette, rekabet baskısına dayanan endüstri içi ticaretin artması nedeniyle sermaye yoğun teknikler daha sık kullanılır

\footnotetext{
* Doç.Dr., Adnan Menderes Üniversitesi Aydın İktisat Fakültesi İktisat Bölümü, Merkez Kampüs, Aydın. (Makale Gönderim Tarihi: 28.03.2018 / Yayına Kabul Tarihi: 14.10.2018
} 
hale gelmiştir. Sermaye yoğun teknoloji kullanmanın önemli ekonomik sonuçları ve yarattığ 1 sorunlar bulunmaktadır. Bu sonuçların en önemlisi, teknolojik yenilik içermeyen ya da aynı teknoloji kullanılarak yapılan üretimlerin kârlılıklarının giderek azalmasıdır. Aynı makineyi kullanan, aynı teknolojiyle üreten, hammadde ve girdi gereksinimini ortak piyasalardan sağlayan, özet olarak aynı üretim fonksiyonuna sahip firmaların ürettikleri ürünlerin getirileri hızla azalmaktadır. $\mathrm{Bu}$ durumu aşabilmenin yolu ya işgücü girdisinin ya da sermayenin maliyetini düşürmekten geçmektedir. Sonuç olarak ilgili piyasada ücretler yükselmemekte ya da aynı üretimi daha çok makineyle gerçekleştirmek gerekmektedir. Tekstil sektörü bu tip piyasaların en önemli örneğini oluşturmaktadır.

Tekstil, ülkelerin vazgeçemedikleri, önemli ölçüde stratejik, çok sayıda işgücünün istihdam edildiği sosyoekonomik yönü ağır basan bir yapıdadır. Ulusal bir marka yaratamamış, maliyet rekabeti ile üretim yapan, mark up fiyatlama* yapamayan ülkelerin küresel tekstil sektöründeki konumları giderek kötüleşmektedir. Türkiye'de aynı kapsamda değerlendirilebilir. Tekstil sektörünün Türkiye'de yarattığı istihdam ve sağladığ1 döviz geliri oldukça önemlidir. Ancak girdi yapısı açısından sektör giderek ithalata bağlanmaktadır. Tekstil sektörünün, küresel sistemin şartlarına göre düzenlenmesi gerekmektedir. $\mathrm{Bu}$ düzenleme yine piyasa kuvvetleri tarafindan yavaş yavaş gerçekleştirilmektedir.

Çalışmamızın amacı Türk tekstil sektöründeki rekabet gücünün sorgulanması ve ürün haritalamasının yapılmasıdır. Bu kapsamda 2001-2016 tarihlerini kapsayan yıllık ITC istatistikleri kullanılmıştır. Analizlerin hedefi çeşitli ölçüm modellerine göre Türkiye'nin küresel sistemdeki konumunun sorgulanmasıdır. Çalışma literatürde ilk kez Türk Tekstil Sektörü'nün rekabet gücünü Ürün Haritalaması Yöntemi ile irdelemektedir.

\section{YERI}

\section{KÜRESEL EKONOMIK SISTEMDE TEKSTILL SEKTÖRÜNÜN}

Küresel diş ticaret içinde tekstil sektörünün payı düşme eğilimi göstermektedir. 2007 Küresel Krizi ile birlikte gelişmiş ülkelerin ekonomilerinde meydana gelen durgunluk, gelişmekte olan ülkeleri daha az etkilemiştir. Gelişmekte olan ekonomiler genellikle tekstil ve tarım ihracatçısıdır. Bu ürünlerin gelir ve fiyat esneklikleri düşüktür. Bu nedenle fiyat ve gelir değişmelerinden fazla etkilenmemektedirler. Sözü edilen nedenlerden dolayı Kriz, tekstil dış ticaretinin toparlanmasını sağlasa da 1995 yılına kıyasla küresel dış ticaret içinde tekstilin payı net olarak azalmıştır.

\footnotetext{
* Mark up fiyatlandırma, ürün maliyetine belirli bir kar marjı eklenerek yapılan fiyatlandırmayı ifade etmektedir. Satıcının piyasada güçlü pozisyonda olması bu tip bir fiyatlandırmaya olanak tanımaktadır.
} 
Grafik 1: Küresel Dış Ticaret İçinde Tekstil Sektörünün Pay1 (1995 - 2016)

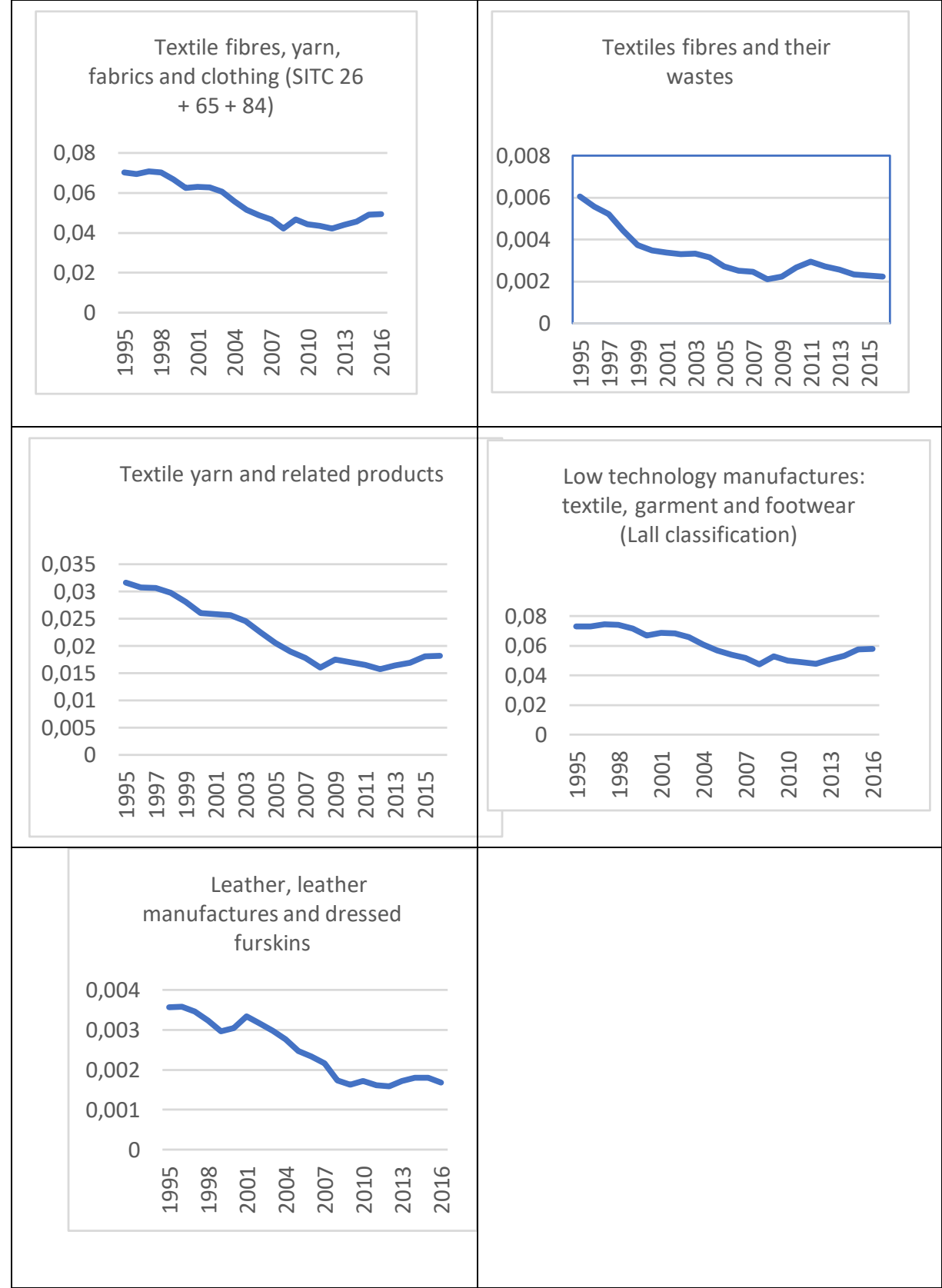

Kaynak: UNCTAD, http://unctadstat.unctad.org/, UNCTAD istatistiklerinden yararlanılarak çalışmamızda üretilmiştir.

Küresel ekonomik sistem içinde tekstil sektörünün oransal olarak azalan payı, sektörün geleceğinin durumunu da sergilemektedir. Sektör, endüstri içi ticaretin nadiren yapıldığ 1 bir alandır. Bu nedenle marka rekabetinin fazla olmadığı, rekabetin işçi ücretlerine dayanan maliyet rekabeti ile sınırlı kaldığ1 
görülmektedir. Sektörün tartışmasız lideri Çin ve Avrupa Birliği ülkeleridir. Çin'in 2001 yılında WTO üyesi olması ve 2008 yılında Çin'e tekstil alanında uygulanan tüm kotaların kaldırılması sonucunda $A B D$ ve $A B$ piyasalarında da lider ülke haline gelmiştir.

\section{A.Türk Tekstil Sektörünün Küresel Sistemde Yeri ve Önemi}

Tablo 1: Fasıl Adları ve İhracatın İthalatı Karşılama Oranı (2001 - 2016 Karşılaştırması) Kaynak: Kaynak: http://www.intracen.org/ ITC verilerinden yararlanılarak çalışmamızda hesaplanmıştır.

Tekstil halen dış ticaret açısından gelir sağlayıcı ve işgücü piyasasında

\begin{tabular}{|c|c|c|c|c|}
\hline \multirow[t]{2}{*}{ Fasıl } & \multirow[t]{2}{*}{ Fasıl Adı } & \multicolumn{3}{|c|}{$\begin{array}{c}\text { İhracatın İthalatı Karşılama } \\
\text { Oranı \% }\end{array}$} \\
\hline & & 2001 & 2016 & Değișim \\
\hline 50 & İpek & 20,60 & 7,46 & - \\
\hline 51 & Yün, kıl, at kılı, bunların iplik ve dokumaları & 53,38 & 50,55 & - \\
\hline 52 & Pamuk, pamuk ipliği ve pamuklu mensucat & 88,68 & 74,84 & - \\
\hline 53 & $\begin{array}{l}\begin{array}{l}\text { Dokumaya elverişli bitkisel lifler kâğıt ipeği ve } \\
\text { dokumaları }\end{array} \\
\end{array}$ & 7,39 & 12,37 & + \\
\hline 54 & Dokumaya elverişli suni ve sentetik lifler & 83,00 & 69,69 & - \\
\hline 55 & Sentetik ve suni devamsız lifler & 116,45 & 67,39 & - \\
\hline 56 & Vatka, keçe, dokunmamış mensucat, özel iplik, sicim & 63,57 & 183,66 & + \\
\hline 57 & Halılar, dokumaya elverişli maddeden yer kaplamaları & 509,64 & 2935,48 & + \\
\hline 58 & $\begin{array}{l}\text { Özel dokunmuş mensucat, dantela, duvar halıları, } \\
\text { işlemeler }\end{array}$ & 255,25 & 249,04 & - \\
\hline 59 & Emdirilmiş, sıvanmış, kaplanmış mensucat, teknik eşya & 179,87 & 94,01 & - \\
\hline 60 & Örme eşya & 321,77 & 345,59 & + \\
\hline 61 & Örme giyim eşyası ve aksesuarları & 4348,69 & 1120,53 & - \\
\hline 62 & Örülmemiş giyim eşyası ve aksesuarları & 2334,62 & 349,80 & - \\
\hline 63 & $\begin{array}{l}\text { Mensucattan mamul diğer eşya, kullanılmış eşya, } \\
\text { paçavralar }\end{array}$ & 4026,05 & 943,31 & - \\
\hline 64 & Ayakkabılar, getrler, tozluklar vb eşya ve aksamı & 149,74 & 95,89 & - \\
\hline
\end{tabular}

istihdam yaratıcı nitelik taşımaktadır. Türk tekstil sektörü açısından 50-64 (dahil olmak üzere) arada kalan tüm fasıllar önem taşımaktadır. Bu fasıllar ve hangi mal gruplarını ifade ettikleri yukarıdaki tabloda verilmiştir.

Türk tekstil sektörü eğitimli işgücü, üretim kalitesi ve nihai ürünlerdeki ihracat kapasitesi açısından dünya ticaretinde önemli yer ve öneme sahiptir. Ancak sektör yüksek kar sağlamaya olanak sağlayacak markalar geliştirememiştir. Türk tekstil sektörü için 2001 ve 2016 yılları verilerini kullanarak basit bir analiz yapıldığında 2001 yılında 6 fasılda ihracatın ithalatı karşılayamadığ1 görülmüştür. 2016 yılı için sayı 8'e yükselmiştir. Diğer yandan dört fasıl hariç tüm fasıllarda ihracatın ithalatı karşılama oranı azalmıştır. 55, 59 
ve 64 numaralı fasıllarda ise 2001 y1lında ihracat ithalatı karşılamaya yeterken 2016 yılında yetmemektedir. Sadece bir fasilda (56) 2001 yılında ihracat ithalat1 karşılamaya yetmezken 2016 yılında yeter hale gelmiştir.

Tablo 1'e göre Türkiye, 56 numaralı fasıl hariç tutulmak üzere tüm tekstil hammaddelerinde dışa bağımlı hale gelmiştir. İhracatın ithalatı karşılama oranları ise azalmaktadır. 2016 yılı UN COMTRADE ve ITC verilerine dayanılarak ilgili fasılların Türk dış ticareti ve dünya tekstil ticareti içindeki payı aşağıdaki şekilde hesaplanmıştır.

Tablo 2: İlgili Sektör Fasıllarının Dünya ve Türkiye'nin Dış Ticareti İçindeki Yerleri (2016)

\begin{tabular}{|c|c|c|c|c|c|c|c|c|}
\hline \multirow{3}{*}{ Fasıl } & \multicolumn{4}{|c|}{$\begin{array}{l}\text { Dünya Ticaretinde Aynı Fasıl } \\
\text { İçinde }\end{array}$} & \multicolumn{4}{|c|}{ Türkiye’nin Dış Ticaretinde Tüm Fasıllar İçinde } \\
\hline & \multicolumn{2}{|c|}{ İHRACAT } & \multicolumn{2}{|c|}{ İTHALAT } & \multicolumn{2}{|c|}{ İHRACAT } & \multicolumn{2}{|c|}{ İTHALAT } \\
\hline & Sirası & Payı & Sırası & Payı & Sırası & Payı & Sırası & Payı \\
\hline $\mathbf{5 0}$ & 25 & 0,10 & 15 & 1,80 & 95 & 0,002 & 91 & 0,02 \\
\hline 51 & 18 & 0,90 & 13 & 1,90 & 69 & 0,086 & 63 & 0,12 \\
\hline 52 & 7 & 3,20 & 4 & 5,00 & 19 & 1,206 & 17 & 1,16 \\
\hline 53 & 36 & 0,70 & 4 & 6,20 & 79 & 0,021 & 64 & 0,12 \\
\hline 54 & 9 & 3,30 & 4 & 5,20 & 22 & 1,043 & 18 & 1,07 \\
\hline 55 & 8 & 3,60 & 3 & 5,30 & 24 & 0,924 & 20 & 0,98 \\
\hline 56 & 9 & 2,60 & 19 & 1,50 & 48 & 0,430 & 57 & 0,17 \\
\hline 57 & 2 & 13,10 & 39 & 0,40 & 17 & 1,342 & 81 & 0,03 \\
\hline 58 & 6 & 4,00 & 16 & 1,80 & 52 & 0,340 & 70 & 0,10 \\
\hline 59 & 17 & 1,20 & 20 & 1,40 & 60 & 0,206 & 58 & 0,16 \\
\hline 60 & 5 & 4,60 & 14 & 1,50 & 21 & 1,051 & 51 & 0,22 \\
\hline 61 & 4 & 4,00 & 36 & 0,40 & 4 & 6,209 & 34 & 0,40 \\
\hline 62 & 9 & 2,70 & 24 & 0,80 & 7 & 4,157 & 24 & 0,85 \\
\hline 63 & 6 & 3,20 & 43 & 0,30 & 16 & 1,371 & 68 & 0,10 \\
\hline 64 & 24 & 0,50 & 33 & 0,50 & 43 & 0,494 & 38 & 0,37 \\
\hline
\end{tabular}

Kaynak: http://www.intracen.org/ ITC verilerinden yararlanılarak çalışmamızda hesaplanmıştır.

Türkiye, dünya tekstil ihracatında 10 fasılda ilk on ülke içinde yer almaktadır. Özellikle halı (57) alanında dünyanın ikinci büyük üreticisidir. Diğer yandan hammadde ithalatında da 4 fasıl sıralamada ilk dört içinde yer almaktadır. Türk tekstil sektörü dünya ticaretinde pek çok fasılda önemli konumda bulunmakla beraber, tekstilin Türkiye'nin toplam ticaretindeki yeri ve önemi oransal olarak azalmaktadır. 61 (4) ve 62 (7) numaralı fasıllar hariç, ihracatta ilk on içinde yer alan tekstil faslı bulunmamaktadır. İthalatta ise tekstil ürünleri oldukça alt sıralarda yer almaktadır.

Dünya tekstil piyasalarında ön siralarda görülen Türk tekstil sektörü Türk ekonomisi içindeki yerini ve önemini yavaş yavaş kaybetmektedir. Türk diş ticaret içinde 61 ve 62 numaralı fasıllar ilk onda yer almakta ancak sıralamadaki yerleri giderek aşağılara inmektedir. Tekstil, markalı ürünler hariç tutulursa yüksek kazanç sağlamayan, emek yoğun bir üretim alanını oluşturmaktadır. Bu nedenle ülkeler tekstil sektörleri ile belirli bir sermaye birikimi yakaladıktan sonra diğer sektörlerini ön plana çıkarmışlardır. Gelişmiş ülkeler tarafından tekstil sektörü iç piyasaya yetecek şekilde korunmaktadır. 
Ahmet Can Bakkalcı / Küresel Ekonomik Sistemde Türk Tekstil Sektörünün Ürün Haritalaması Yöntemiyle Analizi

Tablo 3: Tekstil İhracatı Sıralamasında İlk On Ülke (2016)

\begin{tabular}{|c|c|}
\hline & Tekstil İhracatı Sıralamasındaki İlk On ülke (2016) \\
\hline 0 & Çin, İtalya, Hindistan, Romanya, Fransa, Vietnam, Güney Kore, Japonya, Almanya, Hong Kong \\
\hline 1 & $\begin{array}{l}\text { Avustralya, İtalya, Çin, Almanya, Yeni Zelanda, İngiltere, Çek Cum. Güney Afrika, Hong Kong, } \\
\text { Moğolistan }\end{array}$ \\
\hline 2 & Çin, Hindistan, ABD, Pakistan, Vietnam, Hong Kong, Türkiye, İtalya, Brezilya, Avustralya \\
\hline 3 & Çin, Bangladeş, Fransa, Hindistan, Belçika, İtalya, Sri Lanka, Brezilya, Belarus, İngiltere \\
\hline 4 & Çin, Güney Kore, Tayvan, Almanya, Japonya, Hindistan, İtalya, ABD, Türkiye, BAE \\
\hline 5 & Çin, ABD, Hindistan, Endonezya, Almanya, Güney Kore, Japonya, Türkiye, Avusturya, Tayland \\
\hline 6 & Çin, Almanya, ABD, İtalya, Japonya, Fransa, Güney Kore, Hollanda, Türkiye, Tayvan \\
\hline 7 & Çin, Türkiye, Hindistan, Belçika, Hollanda, ABD, Almanya, Mısır, İngiltere, Fransa \\
\hline 8 & Çin, Hong Kong, Tayvan, Almanya, İtalya, Türkiye, ABD, Güney Kore, Fransa, Hindistan \\
\hline 9 & Çin, Almanya, ABD, Güney Kore, Tayvan, İtalya, Japonya, İngiltere, Vietnam, Hollanda \\
\hline $\mathbf{0}$ & Çin, Güney Kore, Tayvan, Hong Kong, Türkiye, İtalya, ABD, Almanya, Japonya, Vietnam \\
\hline 1 & Çin, Bangladeş, Vietnam, Türkiye, Almanya, Hindistan, İtalya, Hong Kong, Kamboçya, Belçika \\
\hline 2 & Çin, Bangladeş, Vietnam, İtalya, Hindistan, Almanya, İspanya, Hong Kong, Türkiye, Fransa \\
\hline 3 & Çin, Hindistan, Pakistan, Almanya, ABD, Türkiye, Vietnam, Hollanda, Meksika, İngiltere \\
\hline 4 & Çin, Vietnam, İtalya, Almanya, Belçika, Endonezya, Fransa, Hollanda, Hong Kong, İspanya \\
\hline
\end{tabular}

Kaynak: http://www.intracen.org/ ITC verilerinden yararlanılarak çalışmamızda hesaplanmıştır.

Gelişmiş ülkeler özellikle markalı ve mark up fiyatlamaya olanak sağlayan ürünleri sattıklarından yüksek kazanç elde etmektedirler. Pek çok tekstil faslının ihracatında gelişmiş ülkelerin ağırlığını göstermektedir. Çin ise küresel tekstil piyasalarını yönlendirmektedir. Hong Kong ve Tayvan'ın da eklenmesiyle Çin dünya tekstil devi niteliğindedir. Diğer yandan tablonun da ifade ettiği gibi pek çok $\mathrm{AB}$ ülkesi de tekstil dış ticaretinde üst sıralarda yer almaktadır. Tekstil sektöründe standart ve basit ürünler gelişmekte olan ülkeler tarafından üretilirken yüksek katma değer sağlayan moda ve marka ürünler gelişmiş ülkeler, özellikle de $A B$ üyesi ülkeler tarafından pazarlanmaktadır (Bilim Sanayi ve Teknoloji Bakanlığı, 2014: 30). 
Harita 1. Tekstil Dış Ticaretinde İlk On İçinde Yer Alan Ülkeler

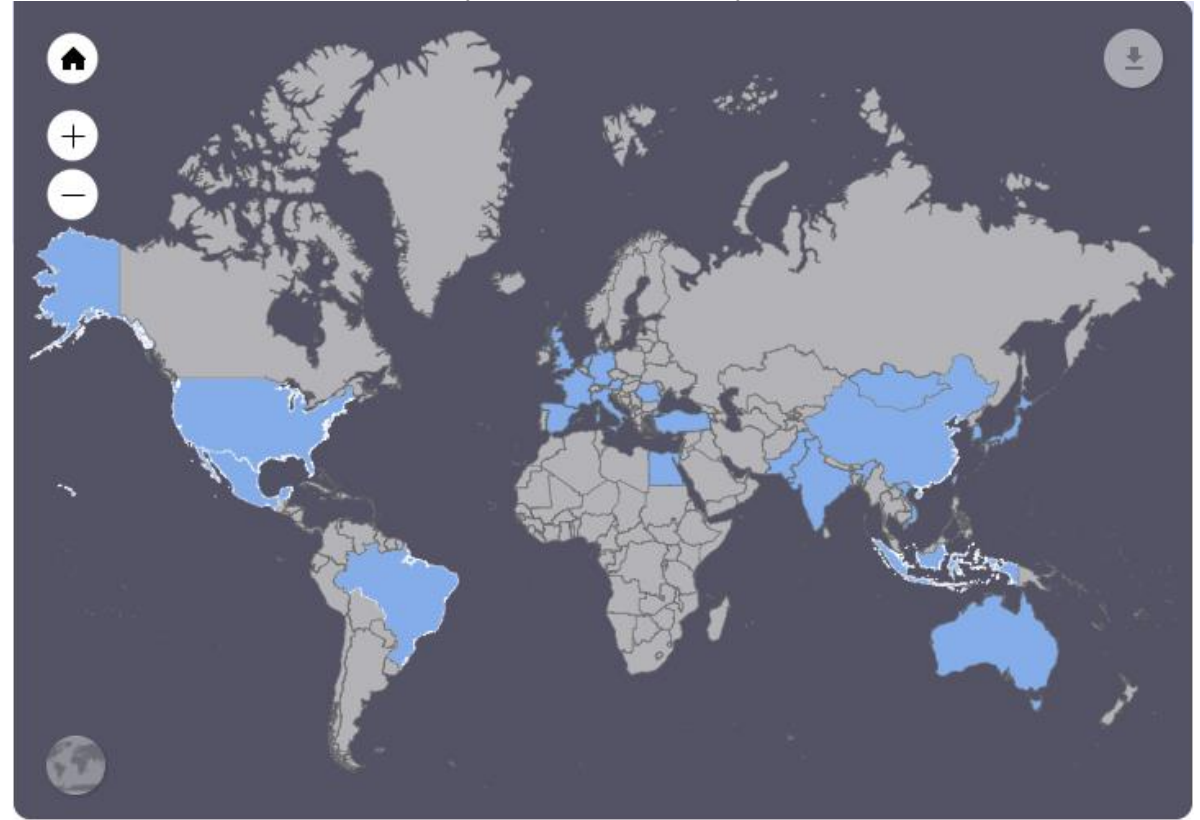

Kaynak: https://www.amcharts.com/visited_countries/, Erişim 24.02.2018. En çok tekstil dış ticareti yapan ülkeler listelenerek çalışmamızda üretilmiştir.

Haritadan da izlenebildiği gibi incelenen 15 fasılda yer alan ilk on içindeki ülkeler genellikle aynıdır. Sektörde Avrupa ve Asya Kıtası'nın Doğu'su önem taşımaktadır. Yine sıcak iklim bölgelerinde tekstil üretiminin yoğunlaşmış olması ilgi çekicidir.

\section{Analizler}

Analizler, dıș ticaret yapılarının ölçümlenmesi çerçevesinde geliştirilen endeksler kullanılarak yapılmıştır. Rekabet analizleri ilk kez Liesner (1958) tarafından 1958 yılında geliştirilmiştir. Liesner Avrupa Ortak Pazarı ve İngiliz endüstrisini karşılaş̧ırmak üzere yaptığ çalışmada 1953 - 1956 yılı verilerini kullanmıştır. Çalışmasında dipnotlarda açıklama olarak İngiliz endüstrisi ihracatını rakiplerin ihracat rakamlarına orantıladığını belirtmiş, net olarak bir formül kullanmamıştır. Bu nedenle Liesner'in modelinden çok Balassa'nın net olarak ifade ettiği ve adını koyduğu Açıklanmış Karşılaştırmalı Üstünlükler Endeksi (RCA) literatürde temel model olarak kullanılagelmiştir.

\section{A. Literatür Özeti}

Rekabet gücü analizleri, ülkelerin diğer ülkelerle yaptıkları ticaretin rekabet gücünü ölçmek üzere geliştirilmiştir. Balassa'nın geliştirdiği RCA analizleri basit, anlaşılır ve çoğu zaman tutarlı sonuçlar veren yapıda olduğundan halen kullanılmaktadır. Kunimoto (1977) Ticaret Yoğunluğu Endeksi'ni kullanarak coğrafi konumun rekabet üzerine etkisini incelemiştir. Bowen (1983) yeni bir RCA modeli önermiş ve bu model UNIDO tarafından da kullanılmıştır. Ballance ve arkadaşları (1985) Bowen'in RCA modelini değerlendirerek uygunluğunu ifade etmişlerdir. Yeats (1985), yaptığı analizlerde RCA Endeksini 
kullanmış ve daha anlaşılır hale getirmiştir. Vollrath (1991) RCA endekslerinin çeşitli varyasyonlarının teorik yapısını incelemiştir. Bu bağlamda endekslerin endüstri içi ve endüstriler arası karşılaştırmaya uygunluklarını tartışmıştır. Lafay (1992), ülkelerin diş ticaret dengelerinden yararlanarak Ticaret Dengesi Endeksi'ni (TBI) geliştirmiştir. TBI, çeşitli sektörler açısından ülkelerin uzmanlaşma düzeyini ifade etmektedir. Amiti (1999) ile birlikte uzmanlaşma ve dış ticaretteki değişim endeksler yanında ekonometrik modellerle de analiz edilmeye başlanmıştır. Kullanılan model işgücü ücretlerini, coğrafi yoğunlaşmayı ve uzmanlaşmayı eşanlı olarak incelemektedir. Uzmanlaşma yani rekabet gücü artışı ile büyümeyi ilişkilendiren bir başka model Dalum ve arkadaşlarına (1999) aittir. Model, Keynesyen yaklaşımın dış ticaret büyümeyi arttırır hipotezini test etmiştir.

Hinloopen ve Marrewijk (2008) RCA için Hillman Koşulu'nun (1980) ampirik testini yapmış ve pek çok ticaret akımı için uygun bulmuşlardır. Benedicts ve arkadaşları (2008) Balassa Modelini semiparametrik modelleme ile uzmanlaşma ve kişi başına düşen GSYİH ilişsisi açısından ele almışlardır.

Widodo (2009), RCA ve TBI yaklaşımını kullanarak ülkelerin Ürün Haritalamasını yapmıştır. Agustin ve arkadaşları (2014) Widodo'nun (2009) kullandığ1 model çerçevesinde Çin ve Endonezya arasındaki ticaretin ürün haritalaması yapmıştır. Laursen (2015) RCA'ya alternatif olabilecek modelleri analiz etmiştir.

Türk tekstil sektörünün rekabet gücünü araştıran pek çok çalışma bulunmaktadır. Akdağ ve arkadaşları (2014) Diyarbakır tekstil sektörünün kümelenme analizini yapmış, rekabet gücünü Elmas Modeli ile değerlendirmişlerdir. Elmas modeli kullanılan diğer bir çalışma Eraslan ve arkadaşları (2008) tarafından yapılmıştır. Kümelenme kapsamında bir başka analiz Alüftekin ve arkadaşlarınca (2009) gerçekleştirilmiştir. Aracı (2010), tekstil sektörünün dünya ekonomik krizlerinden etkilenme sürecini araştırmıştır. Arslan (2008), küresel sistemde tekstil sektörünün rekabet yapısını ve Çin'in Türkiye üzerine etkisini incelemiştir. Özkaya (2010), tekstilde endüstri içi ticareti Grubel Lloyd Endeksi yardımıyla ele almıştır.

Baş (2005), Türk hazır giyim sektörünün pazarlama stratejileri açısından rekabet analizini SWOT ve STEP modelleriyle yapmıştır. Vergil ve Yıldırım (2006) RCA ve panel veri analizlerini kullanarak tekstil özelinde olmamakla beraber SITC Rev 3'e göre diş ticarette rekabet araştırması yapmışlardır. Atış (2014), Türk tekstil sektörünün RCA modeli ve Volrath yaklaşımı ile karşılaştırmalı rekabet gücünü araştırmıştır. Erkan (2013) aynı araştırmayı 19932009 yılları için ele almıştır. Kaya ve Oduncu (2016) RCA, Volrath ve diğer endekslerle 2006-2013 dönemini değerlendirmişlerdir. RCA modeli ile Türkiye ve Çin arasındaki rekabet gücünü araştıran bir başka çalışma Şahin'e (2015) aittir.

Türkçe literatürde tekstil sektörü üzerine çok sayıda çalışma yapılmış olmasına rağmen RSCA, TBI ve Ürün Haritalaması Modelini kullanan az sayıda araştırma bulunmaktadır. Altay ve Savaş (2013) Avrupa Birliği’nin en büyük genişlemesinin katılan ülkelerin ekonomileri üzerindeki etkilerini ve rekabet gücü 
artışını RCA, RSCA ve ekonometrik modelleriyle araştırmışlardır. Bashimov (2017), Türk tekstil sektörü ile ASEAN-5 ülkelerini RCA, RSCA ve TBI ile incelemiş ancak ürün haritalaması yapmamıştır. Aynı şekilde Şahbudak ve Şahin (2016) Grubel-Lloyd, RCA, RSCA ve TBI endeksleriyle Türkiye ve AB-15 tekstil sektörü karşıllaştırmasını yapmışlardır. Topçu ve Sarıgül (2015) ürün haritalamas1 da yaparak biri tekstile ait olmak üzere SITC'de yer alan $(65,67,77$, 78,84 ) beş sektörün rekabet gücünü araştırmışlardır.

\section{B. Analizlerde Kullanılan Modeller}

Analizlerde Balassa, Laursen ve Lafay tarafından geliştirilen RCA, RSCA, TBI endeksleriyle Ürün Haritalaması Modeli kullanılmıştır.

\section{Balassa Endeksleri}

Analizlerde öncelikli olarak Balassa'nın (1965) RCA endeksleri kullanılmıştır. RCA "Revealed Comperative Advantage" yani Açıklanmış Karşılaştırmalı üstünlükler endeksi aşağıdaki şekilde hesaplanmaktadır.
(1) $R C A 1_{T R, T e x}=\frac{\frac{E_{T R, T e x}}{E_{W, T e x}}}{\frac{E_{T R}}{E_{W}}}$
(2) $R C A 2_{T R, T e x}=\frac{\frac{E_{T R, T e x}}{E_{T R}}}{\frac{E_{W, T e x}}{E_{W}}}$

\begin{tabular}{|ll|ll|}
\hline $\boldsymbol{E}_{T R, T e x}$, & Türkiye'nin toplam tekstil ihracatı & $\boldsymbol{E}_{T R, T e x}$, & Türkiye'nin toplam tekstil ihracatı \\
\hline $\boldsymbol{E}_{W, T e x}$ & Dünya toplam tekstil ihracatı & $\boldsymbol{E}_{T R}$ & Türkiye'nin toplam ihracatı \\
\hline $\boldsymbol{E}_{T R}$ & Türkiye'nin toplam ihracatı & $\boldsymbol{E}_{W, T e x}$ & Dünyanın toplam tekstil ihracatı \\
\hline $\boldsymbol{E}_{W}$ & Dünyanın toplam ihracat1 & $\boldsymbol{E}_{W}$ & Dünyanın toplam ihracatı \\
\hline \multicolumn{2}{|c}{ RCA1 endeksi, Türkiye'nin incelemesi yapılan tekstil sektörünün dünya } \\
\hline
\end{tabular}

ihracatı içindeki payını, Türkiye'nin dünya ihracatı içindeki payına oranlamaktadır.

RCA2 endeksi ise, Türkiye'nin toplam ihracatı içindeki tekstilin payını, dünyanın toplam ihracatı içinde tekstilin payına oranlamaktadır. Endekslerin birden büyük olmaları rekabet gücü olduğunu, 0 ile 1 arasında olmaları ise rekabet gücü olmadığını ya da rekabet gücünün kaybedildiğini ifade etmektedir. $\mathrm{Bu}$ noktada her iki endeksin de aynı sonucu verdiğini belirtmekte yarar görülmektedir.

\section{Laursen Endeksi}

Laursen (2015), Balassa endekslerinin daha istikrarlı hale getirilebilmesi için birbirlerini takip eden dönemleri karşılaştırmayı sağlayan doğrusal regresyon modeli kullanmıştır. Böylece ülke ekonomilerinin sektöre duyarlı olarak değişmesi durumunu gidermeye çalışmıştır. Yani Türkiye'nin ekonomisinin tekstil sektöründen etkilenmesi durumunda GSYİH verileri değişeceğinden ihracat ithalat parametreleri de sapmaktadır. Bu sapmanın giderilebilmesi için birbirini takip eden dönemler uyumlaştırılmaya çalışılmıştır.

Laursen'in, Açıklanmış Simetrik Karşılaştırmalı Üstünlükler "Revealed Symmetric Conperative Advantage" RSCA adını verdiği endeks aşağıda yer almaktadır. Laursen, Balassa'nın bir numaralı eşitliğini kullanmıştır. 


$$
\text { (3) } R S C A=\frac{(R C A-1)}{(R C A+1)}
$$

RSCA endeksi -1 ile 1 arasında değer taşımaktadır. Pozitif değer ülkenin rekabet gücü oluğuna işaret etmektedir. Balassa Endekslerinden farklı olarak RSCA endeksleri daha net tahmin yapabilmeye olanak sağlamaktadır.

\section{Lafay Ticaret Dengesi Endeksi}

Lafay (1992) tarafindan önerilen Ticaret Dengesi Endeksi “Trade Balance Index" TBI aşağıdaki şekildedir.

$$
\text { (4) } T B I_{T R, T e x}=\frac{\left(E_{T R, T e x}-M_{T R, T e x}\right)}{\left(E_{T R, T e x}+M_{T R, T e x}\right)}
$$

TBI -1 ile 1 arasında değer alabilmektedir. İncelenen ülke net ithalatçı ise endeks değeri negatif, net ihracatçı ise pozitif olmaktadır.

\section{4. Ürün Haritalaması}

Widodo (2009: 67), TBI ve RSCA endeksleri ile incelenen ürünlerin haritalamasını yapmıştır. Ürün haritalaması RSCA ve TBI endekslerinin bir arada ve Kartezyen koordinat sisteminde kullanılmasıyla elde edilmektedir. Böylece ülkenin incelenen mal grubundaki rekabet gücü ve diş ticaret dengesi bir arada incelenebilmektedir. Çalışmamızda ürün haritalaması yöntemi kullanılmıştır.

\begin{tabular}{|c|c|c|}
\hline $\begin{array}{l}\vec{z} \\
\tilde{C} \\
\sum_{2} \\
v \\
0\end{array}$ & $\begin{array}{c}\text { GRUP B } \\
\text { Rekabet Gücü Var - Karşılaştırmalı Üstün } \\
\text { Net İthalatçı }- \text { İthalata Rakip Sektör Güçlü } \\
\text { RSCA >0 ve TBI <0 }\end{array}$ & $\begin{array}{c}\text { GRUP A } \\
\text { Rekabet Gücü Var - Karş1laştırmalı } \\
\text { Üstün } \\
\text { Net İhracatç1 }- \text { İhraç Sektörü Güçlü } \\
\text { RSCA }>0 \text { ve TBI >0 }\end{array}$ \\
\hline $\begin{array}{l}\tilde{O}_{0} \\
\hat{D} \\
\hat{\theta}\end{array}$ & $\begin{array}{c}\text { GRUP D } \\
\text { Rekabet Gücü Yok } \\
\text { Net İthalatçı }- \text { İthalata Rakip Sektör Zayıf } \\
\text { RSCA }<0 \text { ve TBI }<0\end{array}$ & $\begin{array}{c}\text { GRUP C } \\
\text { Rekabet Gücü Yok } \\
\text { Net İhracatçı }- \text { İhraç Sektörü Zayıf } \\
\text { RSCA }<0 \text { ve TBI }>0\end{array}$ \\
\hline & TBI $<0$ & TBI $>0$ \\
\hline
\end{tabular}

Tablo 4: Rekabet Gücü ve Ticaret Dengesi Haritalaması

Kaynak: Widodo Tri. Comparative Advantage: Theory, Empirical Measures and Case Studies. 2009, 2, No 2, p. 58-65, p. 67.

Tablo 4, incelenen ürünün diş ticaretteki yerini göstermektedir. Tablo verileri grafiğe döküldügünde kuzey ekseni rekabet gücü olan ürünleri, güney ekseni ise rekabet gücü olmayan ürünleri ifade etmektedir. Grafiğin batı tarafına düşen ürünler açısından incelenen ülke net ithalatçı durumundadır. Doğu ekseniyse ülkenin net ihracatçı olduğu ürünleri belirtmektedir.

\section{Analizler}

Türk tekstil sektörünün küresel sistemdeki konumu ile ilgili olarak yapılan analizler orta vadede 2001-2016 verileri kullanılarak çeşitli rekabet gücü ölçümlerine göre hesaplanmıştır. Bu ölçümler için ITC'nin yıllık verileri kullanılmıştır.

Haritalama yöntemiyle endekslemenin yapılmasında iki ana eksen bulunmaktadır. Bunlardan ilki uluslararası rekabet gücünün ölçümlenmesidir. 
İkinci olarak ülkenin makroekonomik göstergeleri içinde tekstil sektörünün dış ticaret parametreleri incelenmektedir.

Analizlerin ilk ayağı olan dış ticaret sektörü içinde tekstilin incelenmesi Keynesyen milli gelir özdeşliği içinde net dış ticaret (X-M) pozisyonunun belirlenmesi amaciyladır. Bu noktada Türkiye'nin tekstil sektörünün ilgili alt birimlerinin ticaret dengeleri araştırılmaktadır.

\section{Türk Tekstil Sektörü İçin Endeks Değerleri}

Türk tekstil sektörünün ilgili fasılları için RCA, RSCA ve TBI Endeksleri aşağıdaki şekilde hesaplanmıştır.

\section{Hammaddeler İçin Yapılan Hesaplamalar}

Türk tekstil sektörü hammadde girdisi açısından dışa bağımlı bulunmaktadır. Hammaddeler için ilgili endeksler açısından yapılan hesaplamalar aşağıdaki tabloda yer almaktadır*.

Tablo 5: Tekstil Hammaddeleri İçin Yapılan Endeks Hesaplamaları (2001 - 2016)

\begin{tabular}{|c|c|c|c|c|c|c|c|c|c|c|}
\hline $\begin{array}{l}\text { FASIL } \\
\text { NO }\end{array}$ & & 2001 & 2003 & 2005 & 2007 & 2009 & 2011 & 2013 & 2015 & 2016 \\
\hline \multirow[t]{3}{*}{50} & RCA & 0,156 & 0,259 & 0,199 & 0,128 & 0,177 & 0,141 & 0,135 & 0,126 & 0,127 \\
\hline & RSCA & $-0,730$ & $-0,588$ & $-0,668$ & $-0,773$ & $-0,700$ & $-0,753$ & $-0,762$ & $-0,776$ & $-0,775$ \\
\hline & TBI & $-0,658$ & $-0,513$ & $-0,730$ & $-0,847$ & $-0,779$ & $-0,853$ & $-0,857$ & $-0,871$ & $-0,861$ \\
\hline \multirow[t]{3}{*}{51} & RCA & 1,826 & 1,780 & 1,916 & 1,965 & 1,784 & 1,676 & 1,673 & 1,349 & 1,078 \\
\hline & RSCA & 0,292 & 0,281 & 0,314 & 0,326 & 0,282 & 0,253 & 0,252 & 0,149 & 0,038 \\
\hline & TBI & $-0,304$ & $-0,439$ & $-0,390$ & $-0,347$ & $-0,337$ & $-0,384$ & $-0,292$ & $-0,307$ & $-0,328$ \\
\hline \multirow[t]{3}{*}{52} & RCA & 4,475 & 3,587 & 3,513 & 3,984 & 3,619 & 3,643 & 3,325 & 3,447 & 3,649 \\
\hline & RSCA & 0,635 & 0,564 & 0,557 & 0,599 & 0,567 & 0,569 & 0,538 & 0,550 & 0,570 \\
\hline & TBI & $-0,060$ & $-0,244$ & $-0,276$ & $-0,274$ & $-0,243$ & $-0,305$ & $-0,216$ & $-0,141$ & $-0,144$ \\
\hline \multirow[t]{3}{*}{53} & RCA & 0,311 & 0,743 & 0,970 & 1,092 & 0,804 & 0,765 & 0,773 & 0,540 & 0,785 \\
\hline & RSCA & $-0,526$ & $-0,147$ & $-0,015$ & 0,044 & $-0,109$ & $-0,133$ & $-0,128$ & $\begin{array}{l}-0,299 \\
\end{array}$ & $-0,121$ \\
\hline & TBI & $-0,862$ & $-0,749$ & $-0,756$ & $-0,715$ & $-0,775$ & $-0,826$ & $-0,816$ & $-0,841$ & $-0,780$ \\
\hline \multirow[t]{3}{*}{54} & RCA & 3,145 & 3,057 & 3,353 & 3,788 & 3,787 & 3,962 & 4,179 & 3,802 & 3,702 \\
\hline & RSCA & 0,518 & 0,507 & 0,540 & 0,582 & 0,582 & 0,597 & 0,614 & 0,584 & 0,575 \\
\hline & TBI & $-0,093$ & $-0,148$ & $-0,112$ & $-0,113$ & $-0,073$ & $-0,162$ & $-0,106$ & $-0,145$ & $-0,179$ \\
\hline \multirow[t]{3}{*}{55} & RCA & 5,532 & 5,050 & 4,873 & 4,120 & 4,204 & 4,281 & 4,181 & 3,945 & 4,050 \\
\hline & RSCA & 0,694 & 0,669 & 0,659 & 0,609 & 0,616 & 0,621 & 0,614 & 0,596 & 0,604 \\
\hline & TBI & 0,076 & $-0,107$ & $-0,083$ & $-0,285$ & $-0,231$ & $-0,298$ & $-0,223$ & $-0,187$ & $-0,195$ \\
\hline \multirow[t]{3}{*}{56} & RCA & 1,182 & 1,309 & 1,747 & 1,481 & 1,592 & 2,332 & 2,674 & 2,717 & 2,907 \\
\hline & RSCA & 0,084 & 0,134 & 0,272 & 0,194 & 0,228 & 0,400 & 0,456 & 0,462 & 0,488 \\
\hline & TBI & $-0,223$ & $-0,253$ & $-0,193$ & $-0,296$ & $-0,241$ & $-0,015$ & 0,135 & 0,161 & 0,295 \\
\hline
\end{tabular}

Kaynak: UNIDO verilerinden yararlanarak çalışmamızda üretilmiştir.

Vatka, keçe, dokunmamış mensucat, özel iplik, sicim ve mamullerini içeren 56 numaralı fasıl hariç tüm girdilerde dışa bağımlılık oldukça yüksek düzeyde seyretmektedir. Önceki zamanlarda pamuk, ipek, pamuklu iplik gibi alanlarda ihracatçı olan Türkiye'nin dış ticaret kompozisyonu aleyhe dönmüştür. Tekstil hammaddesinde dışa bağımlılık devam etmektedir.

\footnotetext{
* Tablonun formata sığabilmesi için hesaplamalar çiftli yıllar atlanarak verilmiştir. Ancak grafikler ilgili verileri içermektedir.
} 
Grafik 2: Tekstil Hammaddeleri İçin Ürün Haritalamas1

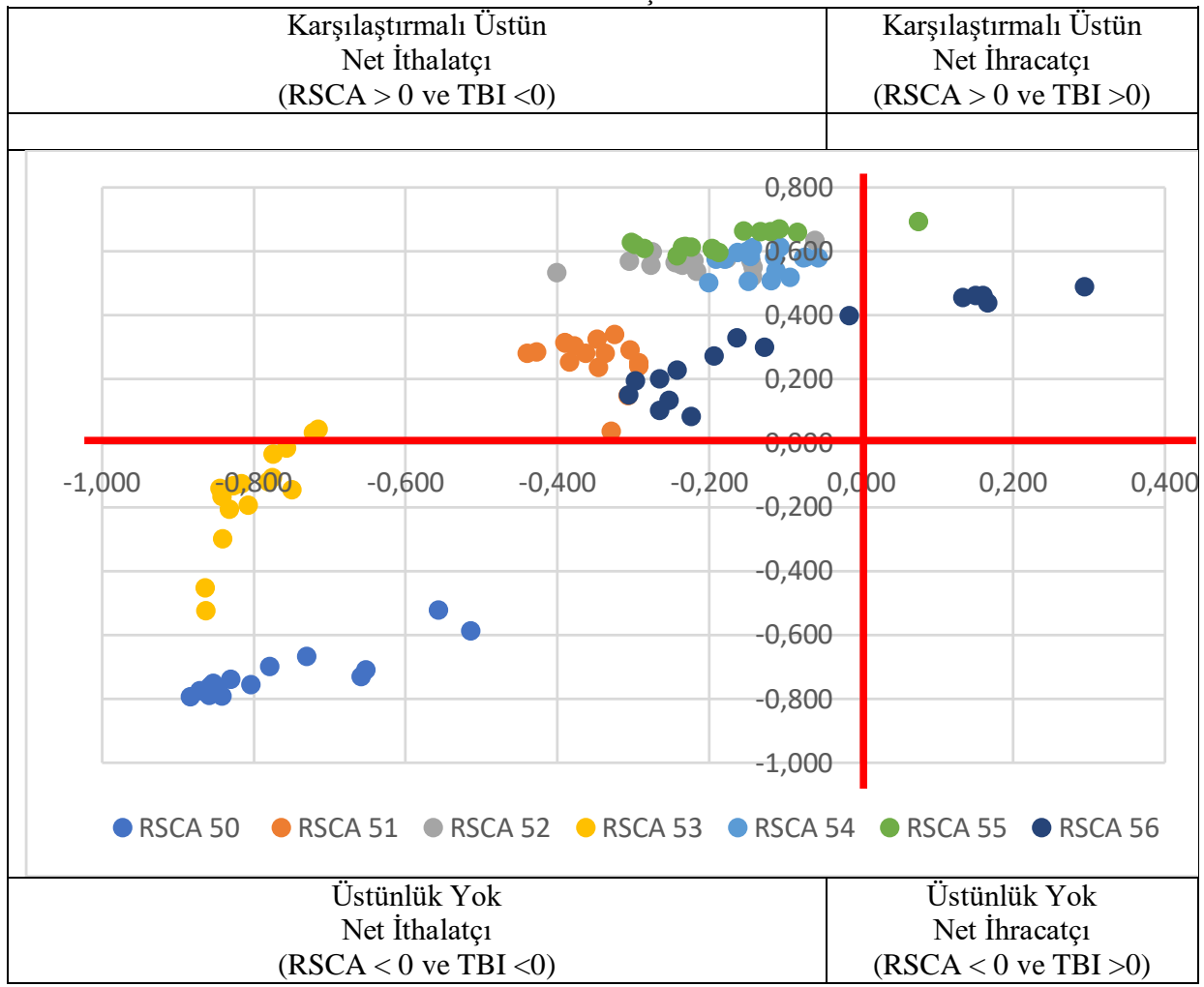

Kaynak: UNIDO verilerinden yararlanarak çalışmamızda üretilmiştir.

Ürün haritalaması grafiği önemli sayıda yılda ve ürün grubunda rekabet gücünün olduğunu ancak dişa bağımlılığın da bulunduğunu ifade etmektedir. Hammadde grubunda 56 numaralı fasıl hariç Türkiye'nin net ihracatçı olduğu ürün grubu kalmamıştır.

\section{Halı Grubu İçin Yapılan Hesaplamalar}

Halı grubu 57 ve 58 numaralı fasıllardan oluşmaktadır. Türkiye bu fasıllarda dünyanın en önemli üretici ve dış ticaret ortaklarındandır. Türkiye 57 numaralı fasılda Çin'den sonra gelen en büyük ihracatçıdır. Diğer yandan 58 numaralı fasılda da 6 ncı büyük ihracatçıdır.

Tablo 6: Halı Grubu İçin Yapılan Endeks Hesaplamaları (2001 - 2016)

\begin{tabular}{|l|l|l|l|l|l|l|l|l|r|r|}
\hline $\begin{array}{l}\text { FASIL } \\
\text { NO }\end{array}$ & & & & & & & & & & \\
& & 2001 & 2003 & 2005 & 2007 & 2009 & 2011 & 2013 & 2015 & 2016 \\
\hline 57 & RCA & 6,390 & 6,422 & 8,172 & 9,240 & 10,861 & 13,859 & 17,136 & 15,535 & 14,638 \\
\cline { 2 - 12 } & RSCA & 0,729 & 0,731 & 0,782 & 0,805 & 0,831 & 0,865 & 0,890 & 0,879 & 0,872 \\
\cline { 2 - 12 } & TBI & 0,672 & 0,688 & 0,645 & 0,675 & 0,767 & 0,784 & 0,844 & 0,902 & 0,934 \\
\hline 58 & RCA & 7,426 & 5,996 & 6,690 & 6,142 & 4,965 & 5,487 & 5,660 & 4,340 & 4,492 \\
\cline { 2 - 12 } & RSCA & 0,763 & 0,714 & 0,740 & 0,720 & 0,665 & 0,692 & 0,700 & 0,625 & 0,636 \\
\cline { 2 - 12 } & TBI & 0,437 & 0,176 & 0,400 & 0,480 & 0,545 & 0,453 & 0,506 & 0,428 & 0,427 \\
\hline
\end{tabular}

Kaynak: UNIDO verilerinden yararlanarak çalışmamızda üretilmiştir. 
Halı grubu ürünlerde Türkiye dünya üretiminde önemli düzeyde söz sahibidir. Durum ürün haritalaması grafiğinden de anlaşılabilmektedir.

Grafik 3: Halı Grubu İçin Ürün Haritalaması

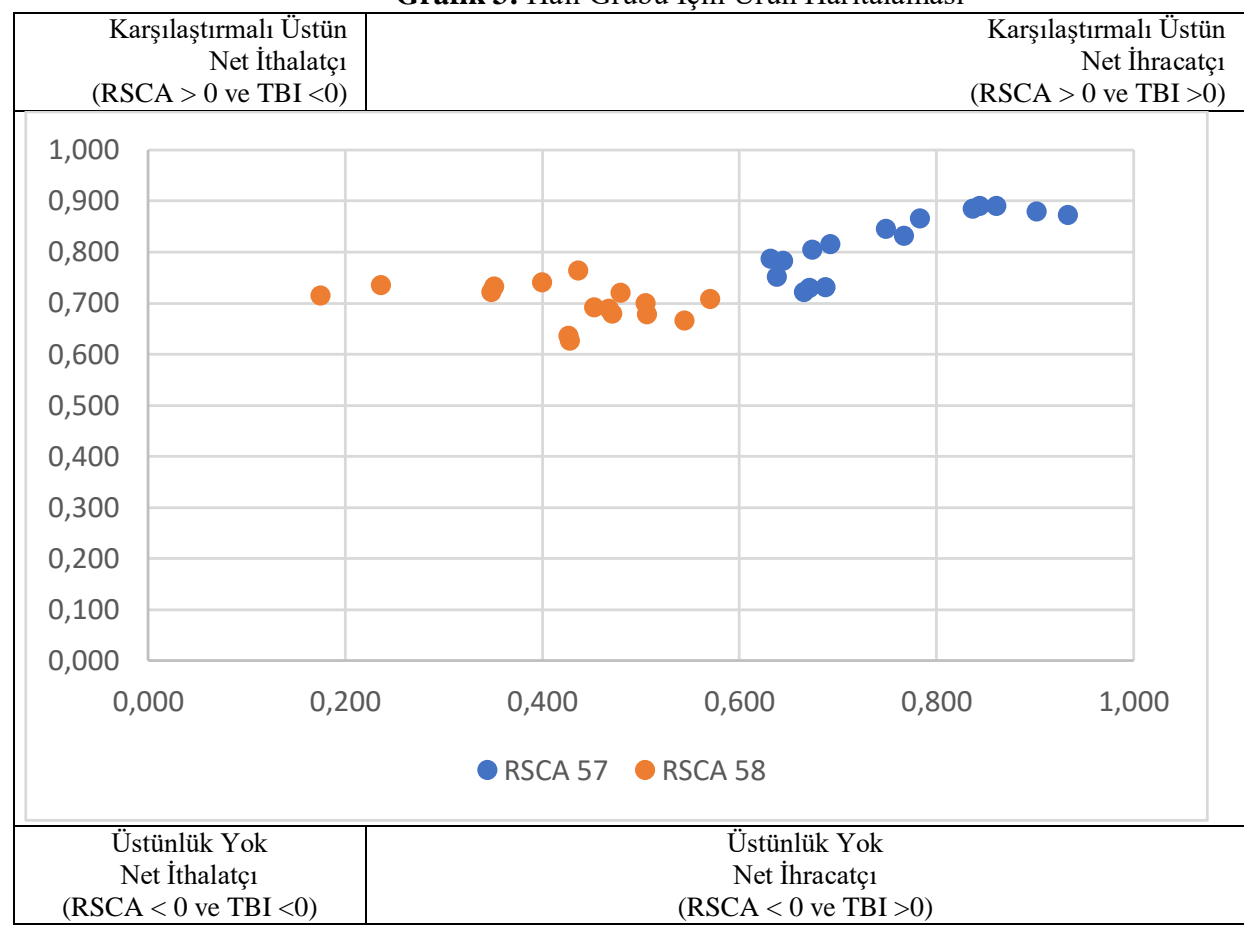

Kaynak: UNIDO verilerinden yararlanarak çalışmamızda üretilmiştir.

$\mathrm{Bu}$ grupta negatif alanda haritalama verisi bulunmamaktadır. Bu nedenle tüm veriler kadranın kuzeybatısında bulunan $(+,+)$ eksende yer almaktadır.

\section{Hazır Giyim ve Nihai Tekstil Ürünleri İçin Yapılan Hesaplamalar}

Hazır giyim ve tekstil sektörü 59 ve 64 numaralı fasıllar hariç tutulmak üzere rekabet gücü ve dış ticaret fazlasına sahip bulunmaktadır. Son yıllarda 59 numaralı faslın dış ticaret dengesi az da olsa açık vermeye başlamıştır. Bu alanda da tüm fasıllarda dış ticaret dengesi yıllar bazında Türkiye aleyhine kötüleşmekte, RSCA endeksi genel olarak azalmaktadır.

Tablo 7: Hazır Giyim ve Nihai Tekstil Ürünleri İçin Yapılan Endeks Hesaplamaları (2001 - 2016)

\begin{tabular}{|c|c|c|c|c|c|c|c|c|c|c|}
\hline $\begin{array}{l}\text { FASIL } \\
\text { NO }\end{array}$ & & 2001 & 2003 & 2005 & 2007 & 2009 & 2011 & 2013 & 2015 & 2016 \\
\hline \multirow[t]{3}{*}{59} & RCA & 2,289 & 2,258 & 2,228 & 2,075 & 1,887 & 1,834 & 1,649 & 1,440 & 1,378 \\
\hline & RSCA & 0,392 & 0,386 & 0,380 & 0,350 & 0,307 & 0,294 & 0,245 & 0,180 & 0,159 \\
\hline & TBI & 0,285 & 0,261 & 0,118 & 0,175 & 0,133 & $-0,013$ & $-0,012$ & $-0,028$ & $-0,031$ \\
\hline \multirow[t]{3}{*}{60} & RCA & 3,164 & 3,066 & 4,038 & 5,351 & 5,487 & 6,459 & 6,359 & 4,934 & 5,137 \\
\hline & RSCA & 0,520 & 0,508 & 0,603 & 0,685 & 0,692 & 0,732 & 0,728 & 0,663 & 0,674 \\
\hline & TBI & 0,526 & 0,417 & 0,540 & 0,638 & 0,651 & 0,452 & 0,580 & 0,538 & 0,551 \\
\hline
\end{tabular}




\begin{tabular}{|l|l|l|l|l|l|l|l|l|l|l|}
\hline 61 & RCA & 8,675 & 8,973 & 7,475 & 5,998 & 5,309 & 5,376 & 4,968 & 4,618 & 4,529 \\
\cline { 2 - 11 } & RSCA & 0,793 & 0,799 & 0,764 & 0,714 & 0,683 & 0,686 & 0,665 & 0,644 & 0,638 \\
\cline { 2 - 11 } & TBI & 0,955 & 0,952 & 0,926 & 0,874 & 0,823 & 0,771 & 0,815 & 0,824 & 0,836 \\
\hline 62 & RCA & 5,026 & 4,962 & 4,707 & 4,111 & 3,536 & 3,463 & 3,407 & 3,076 & 3,051 \\
\cline { 2 - 11 } & RSCA & 0,668 & 0,665 & 0,650 & 0,609 & 0,559 & 0,552 & 0,546 & 0,509 & 0,506 \\
\cline { 2 - 11 } & TBI & 0,918 & 0,886 & 0,836 & 0,728 & 0,625 & 0,464 & 0,508 & 0,535 & 0,555 \\
\hline 63 & RCA & 10,927 & 10,239 & 8,217 & 6,657 & 5,634 & 5,105 & 4,364 & 3,547 & 3,632 \\
\cline { 2 - 10 } & RSCA & 0,832 & 0,822 & 0,783 & 0,739 & 0,699 & 0,672 & 0,627 & 0,560 & 0,568 \\
\cline { 2 - 10 } & TBI & 0,952 & 0,957 & 0,936 & 0,889 & 0,883 & 0,824 & 0,858 & 0,813 & 0,808 \\
\hline 64 & RCA & 0,522 & 0,537 & 0,458 & 0,491 & 0,453 & 0,518 & 0,697 & 0,571 & 0,583 \\
\cline { 2 - 10 } & RSCA & $-0,314$ & $-0,301$ & $-0,372$ & $-0,341$ & $-0,376$ & $-0,318$ & $-0,179$ & $-0,273$ & $-0,264$ \\
\cline { 2 - 9 } & TBI & 0,199 & $-0,019$ & $-0,313$ & $-0,286$ & $-0,322$ & $-0,328$ & $-0,157$ & $-0,085$ & $-0,021$ \\
\hline
\end{tabular}

Kaynak: UNIDO verilerinden yararlanarak çalışmamızda üretilmiştir.

Durum ürün haritalaması grafiğinden de takip edilebilmektedir.

Grafik 4: Hazır Giyim ve Nihai Tekstil Ürünleri İçin Ürün Haritalamas1

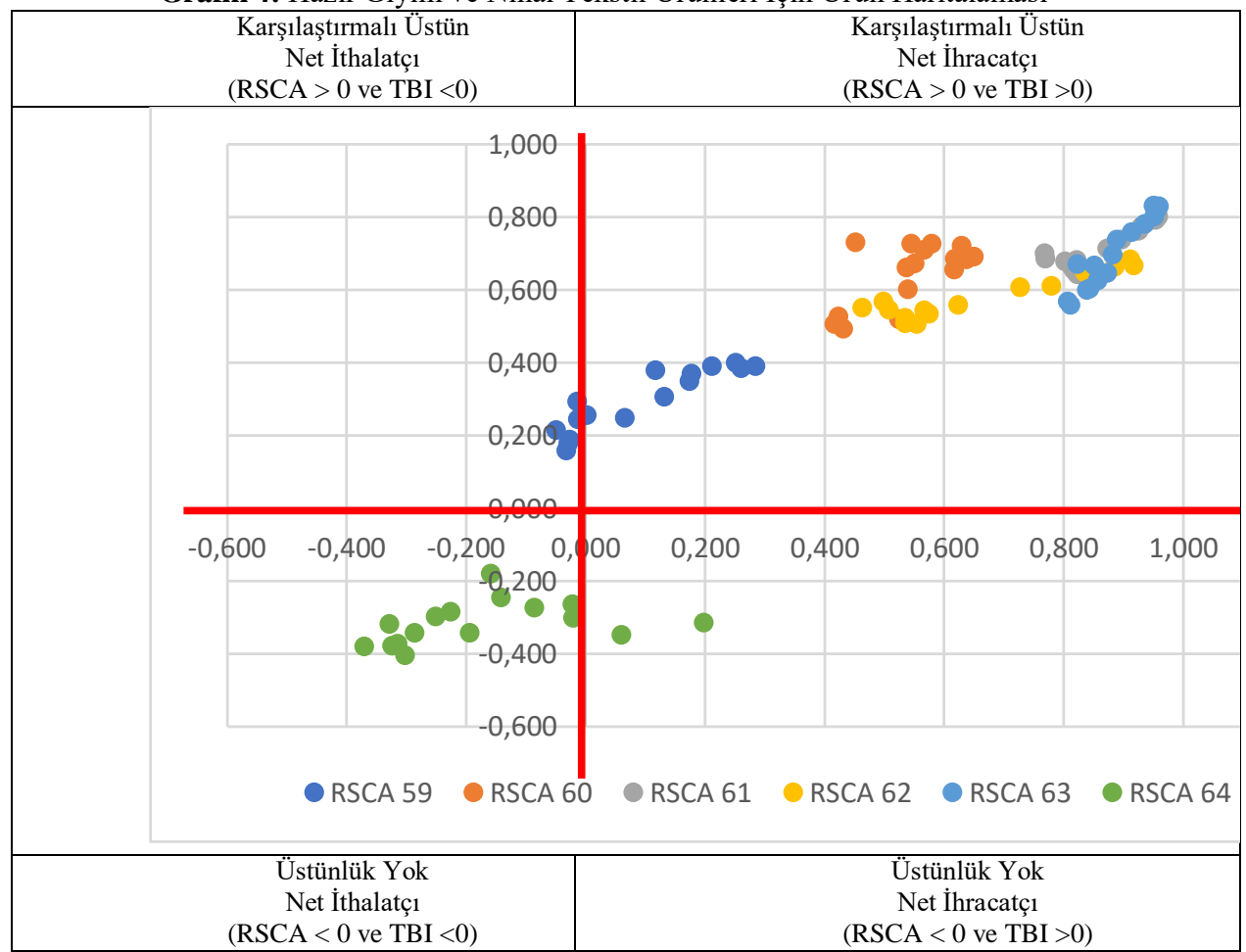

Kaynak: UNIDO verilerinden yararlanarak çalışmamızda üretilmiştir.

\section{SONUC}

Çalışma literatürde ilk kez Türk Tekstil Sektörü'nün rekabet gücünü Ürün Haritalaması Yöntemi ile irdelemiştir.

Küresel ekonomik sistem değişmekte ve sermaye yoğun malların ticaretinin yapıldığı, geleneksel sektörlerin göreli önemlerini kaybettikleri bir yapıya doğru ilerlemektedir. Tekstil sektörünün üretim fonksiyonu tüm ülkeler tarafından bilindiğinden rekabet, marka rekabetine doğru evrilmektedir. Bu sistem 
içinde yer alan tekstil sektörü için de durum aynıdır. Sektör Türk ekonomisi içindeki göreli önemini de yitirmektedir.

Sektörde Çin ve Avrupa Birliği ülkeleri en büyük ihracatçı kategorisini paylaşmaktadır. Türkiye de bu gruba dahil bulunmaktadır. Ancak Türkiye bu sektörde net hammadde ithalatçısı olmuştur.

Halı ve ürünlerinde dünyanın ikinci büyük ihracatçısı olan Türkiye, mamul mallarda da üstünlüğü korumaktadır. Ancak Türkiye, hammadde ve girdileri dışarıdan sağladığından bu durum üretimde zayıf halkayı oluşturmaktadır. Diğer yandan Türkiye asıl getiriyi sağlayan markalaşmayı gerçekleştiremediğinden, mark up fiyatlama uygulayamamaktadır. Bu nedenle düşük kâr marjıyla çalışmaktadır.

\section{KAYNAKÇA}

Agustin, G., Ananda, C., Maski, G., Saputra, P. M. (2014), The Product Mapping Analysis Of Manufacturing Industry Products in Bilateral Trade Between Indonesia and China in 1995 - 2011, International.Journal.of Economics and Research, Vol: 5i, 2, 37-49.

Altay, H. Savaş, M. (2013). Avrupa Birliği'ne Beşinci Genişleme Süreciyle Üye Olan Ülkelerin Rekabet Güçlerindeki Değişimin Analizi, Dumlupınar Üniversitesi Sosyal Bilimler Dergisi, Say1 35, Ocak, 55-80.

Altay B., Sümerli S. (2015). Comparatıve Advantage and The Product Mapping of Exporting Sectors in Turkey, Akademik ve Sosyal Araştırmalar Dergisi, Y1l: 3, Sayı: 18, Aralık, 330-348.

Alüftekin, N., Yüksel, Ö., Taş A., Çakar, G., Bayraktar, F., (2009), Küresel Krizden Çıkışta Kümelenme Modeli Tekstil ve Hazır Giyim Sektörü Örneği, ZKÜ Sosyal Bilimler Dergisi, Cilt:5, Say1: 10, 1-19.

Akdağ, R., Mete, M., Emhan A., (2014). Diyarbakır Tekstil ve Hazır Giyim Sektörünün Elmas Modeli ile Kümelenme Analizi, Süleyman Demirel Üniversitesi İktisadi ve İdari Bilimler Fakültesi Dergisi, Cilt: 19, Say1: 2, 323-341.

Aracı, K. A., (2010), 1929 Büyük Ekonomik Buhran'dan 2008 Ekonomik Krizi'ne Dünya Ekonomik Krizleri Ve Türk Tekstil Sektörüne Etkileri, (Basılmamış Yüksek Lisans Tezi), Namık Kemal Üniversitesi Fen Bilimleri Enstitüsü, Tekirdağ.

Arslan, K., (2008), Küresel Rekabet Baskısı Altında Tekstil ve Hazır Giyim Sektörünün Dönüşüm Stratejileri ve Yeni Yol Haritası, Müsiad Araştırma Raporları: 57, İstanbul: İmak.

Gacaner A. A., (2014), Türkiye'nin Tekstil ve Konfeksiyon Sektörünün Karşılaştırmalı Rekabet Analizi, Ege Akademik Bakış, Cilt: 14, Sayı: 2, Nisan, 315-334.

Balassa, B., (1965), "Trade Liberalization and Revealed Comparative Advantage," Manchester School, Vol. 33, Issue, 2, May, 99-123.

Ballance, R., Helmut F., Tracy M., (1985), "On Measuring Comparative Advantage:A Note on Bowen's Indices." Weltwirtschaftliches Archiv, Vol. 121, 46-350.

Bashimov, G., (2017), Türk Tekstil ve Hazır Giyim Sektörünün Uluslararası Rekabet Gücü: ASEAN-5 Ülkeleri İle Karşılaştırmalı Analiz, Adnan Menderes Üniversitesi Sosyal Bilimler Enstitüsü Dergisi, Cilt: 4, Sayı: 2, 1-15.

Baş, A., (2005), Türk Hazır Giyim Sektörünün Rekabet Analizi ve Global Pazarlama Stratejileri Önerisi, Marmara Üniversitesi Sosyal Bilimler Enstitüsü, İstanbul.

Bilim Sanayi ve Teknoloji Bakanlığı (2014). Türkiye Tekstil, Hazırgiyim ve Deri Ürünleri Sektörleri Strateji Belgesi ve Eylem Planı 2015 - 2018, Ankara: Sanayi Genel Müdürlüğü, s. 30 .

Bowen, H. R., (1983), "On the Theoretical Interpretation of Indices of Trade Intensity and Revealed Comparative Advantage". Weltwirtschaftliches Archiv, Vol. 119, Issue, 3, 464-472.

Dalum, B., Laursen K., Verspagen B., (1999), Does Specialization Matter For Growth, Industrial and Corporate Change, Volume 8, Issue 2, 1 June, 267-288. 
Eraslan, H., Bakan, İ., Helvacığlu K. A., (2008), Türk Tekstil Ve Hazırgiyim Sektörünün Uluslararası Rekabetçilik Düzeyinin Analizi, İstanbul Ticaret Üniversitesi Sosyal Bilimler Dergisi Y11:7 Say1:13 Bahar, 265-300

Erkan, B., (2013), Türkiye'nin Tekstil ve Hazır Giyim Sektörü İhracatında Uluslararası Rekabet Gücünün Belirlenmesi, Anadolu Üniversitesi Sosyal Bilimler Dergisi, Cilt: 13, Say1: 1, 93-109.

Hillman, A., (1980), Observations On The Relation Between 'Revealed Comparative Advantage' and Comparative Advantage as Indicated By Pre-Trade Relative Prices, Weltwirtschaftliches Archiv, 116, 315-21.

Özkaya, H., (2010), Tekstil Sektöründe Endüstri İçi Ticareti Etkileyen Faktörler Üzerine Ampirik Çalışma, Uşak Üniversitesi Sosyal Bilimler Dergisi, Cilt: 3, Sayı: 2, 36-157.

Hinloopen, J., Marrewijk. C., (2008), "Empirical Relevance of the Hillman Condition for Revealed Comparative Advantage: 10 Stylized Facts", Applied Economics, 40:18, 2313-2328.

Kaya, Ö., Oduncu, A., (2016), Türk Tekstil Sektörünün Uluslararası Rekabet Gücü Değerlendirmesi, Akademik Bakış Dergisi, Sayı: 54, Mart Nisan, 418-428.

Kunimoto, K., (1977), "Typology of Trade Intensity Indices." Hitotsubashi Journal of Economics, Vol. 17, 15-32.

Lafay, G., (1992), "The Measurement of Revealed Comparative Advantages", in M.G. Dagenais and P.A. Muet (eds.), International Trade Modeling, London: Chapman \& Hill.

Laursen, K., (2015), Revealed Comparative Advantage and the Alternatives as Measures of International Specialization. Eurasian Business Review, 5(1), 99-115. DOI: 10.1007/s40821-015-0017-1

Liesner, H. (1958), “The European Common Market and British Industry” The Economic Journal, Vol: 68, No: 270, Jun., $302-316$.

Şahbudak, E., Şahin, D., (2016), Tekstil ve Hazır Giyim Sektörünün Dış Ticaret Yapısı: Türkiye ve AB-15 Ülkeleri Örneği, Kesit Akademi Dergisi, Sayı: 4, Haziran. 125-139.

Şahin, D., (2015), Türkiye ve Çin'in Tekstil ve Hazır Giyim Sektöründe Rekabet Gücünün Analizi, Akademik Bakış Dergisi, Sayı: 47, Ocak - Şubat, 155-171.

Vergil, H., Yıldırım, E., (2006), AB-Türkiye Gümrük Birliğinin Türkiye'nin Rekabet Gücü Üzerindeki Etkileri, Erciyes Üniversitesi İktisadi ve İdari Bilimler Fakültesi Dergisi, Sayı 26, Ocak Haziran, 1-21.

Vollrath, T., (1991), A Theoretical Evaluation Of Alternative Trade Intensity Measures Of Revealed Comparative Advantage, Weltwirtschaftliches Archiv, Vol. 127, Issue 2, June, 265-280.

Yeats, A. J., (1985), "On the Appropriate Interpretation of the Revealed Comparative Advantage Index: Implications of a Methodology Based on İndustry Sector Analysis". Weltwirtschaftliches Archiv, Vol. 121, 61-73.

Widodo T., (2009), Comparative Advantage: Theory, Empirical Measures and Case Studies. Review of Economic and Business Studies, Issue 4, November, 57-82.

\section{SUMMARY}

Turkish textile sector is one of the most important sectors in Turkish Economy. As in many developing countries the textile sector has played an important role in the process of industrialization of Turkey. But recently this sector is losing its competition power against Far East rivals. China, India and Pakistan have been entered global textile sector since 2005. There is a constant rise in exchange rate in Turkey. All raw materials and textile machines price are rising in comparison to its rivals.

Turkish market share has been declined after this time. On the other hand there is only a few Turkish brands in the Global textile sectors. For these reason Turkish firms profits are not enough to develop new technological textile goods and R\&D. 
The textile industry is at the forefront of the strategically important areas of many countries. The Turkish textile industry has been a leading sector for many years in Turkish industries. But in the globalizing world, the textile industry has begun to lose its former importance and production function of textile sector is known by all countries.

The raw materials and the capital goods are imported from certain countries. Leading manufacturers in the industry are concentrated in China and European Union. Turkey mainly imports raw materials and exports final goods in textile industry.

The Turkish textile sector, which is at the forefront in the world textile markets, gradually loses its place and importance in the Turkish economy. In Turkish foreign trade, chapters 61 and 62 are in the top ten, but their rank in the rankings is going down.

Turkish textile industry has significant roles in Global textile market especially carpets, textile apparel and clothing. The advantages of the Turkish textile and apparel industry include high production capacity, experience and knowledge in the industry. However, the weak ring in the whole supply chain, namely, retailing and branding are where the most of the value generated. Turkey has a few global brands in textile industry and this cannot allow mark up pricing and high profits.

This article has been investigated Turkish Textile Sector's competition power for the first time in the literature by using Product Mapping Model. 